\title{
Música a partir do barulho; silêncio a partir da música.
}

Music from the noise;

silence from the music.

\section{Mariama Palhares Pucci}

\section{$\underline{\underline{\text { Danilo Ferreira de Camargo }}}$}

1 Especialista em Arte na Educação: Teoria e Prática pela Universidade de São Paulo (USP). Professora de Educação Infantil pela Prefeitura de São Paulo. mariama.palhares@gmail.com

2 Danilo Ferreira de Camargo é bacharel em filosofia pela Faculdade de Filosofia e Ciências Humanas da Universidade de São Paulo e Mestre em educação pala Faculdade de Educação da Universidade de São Paulo. 
RESUMO: O artigo apresenta um projeto de música para crianças de três e quatro anos de idade, realizado em um Centro de Educação Infantil da Prefeitura de São Paulo. Partindo do relato de uma experiência inicial recheada de ruídos e dispersões em sala de aula, e articulando conceitos de alguns autores sobre música, som e educação, buscou-se construir uma análise sobre as dificuldades e possibilidades da prática escolar, assim como criar uma perspectiva de escuta e pesquisa sonora, feitas de maneira "brincante" e divertida.

PALAVRAS-CHAVE: Educação infantil; Arte e educação; Música; Protagonismo infantil;

ABSTRACT: The article presents a music project for three and four years old children, at a Center for Early Childhood Education maintained by the City of São Paulo. Starting from a description of an initial experience, filled with noise and dispersion in the classroom, and articulating concepts of some authors about music, sound and education, we sought to make an analysis of the difficulties and possibilities of school practice, as well as a perspective of listening and sound research, done in a playful and fun way.

KEYWORDS: Children's education; Art and education; Music; Child protagonism; 
O mundo então está cheio de sons. Ouça.

Murray Schafer

"Tá muito barulho!", diziam as crianças incomodadas com o tumulto de sons que vinham da rua, das salas ao lado, e das pessoas que circulavam pelos corredores da escola. Esse era o cenário, um tanto desolador, para quem começava a lecionar. Em 2018, fui professora regente de crianças de três e quatro anos em um Centro de Educação Infantil (CEI), localizado dentro de um Centro de Educação Unificada (CEU), na zona sul da cidade de São Paulo. A turma era composta por 25 crianças e o CEI tinha ao todo 322 alunos. Já o CEU, com seus cursos curriculares e extracurriculares, atendia mais de 2.000 alunos de todas as idades. Logo no começo do semestre, percebi que estar sozinha com essas crianças tão pequenas, tão espertas, tão cheias de vontades e opiniões me traria muitos desafios nessa primeira incursão como professora de educação infantil, embora eu já tivesse experiências anteriores como professora de artes.

Com a algazarra de sons vinda de outros espaços, os alunos passaram a aumentar o volume da voz dia após dia, o que influenciava na agitação de todos e gerava incômodos. Ao final do primeiro mês de trabalho, me dei conta de que nossa comunicação estava muito mais alta do que o necessário. Era difícil acalmar as crianças, ou ter a atenção de todas para iniciar uma atividade ou uma roda de conversa, e minha garganta já demonstrava alguns sinais de irritação devido aos excessos.

Verifiquei que essa situação não é algo raro nas escolas. Estudos realizados por pesquisadores da Universidade Estadual de Campinas com mais de 700 crianças de escolas públicas do interior de São Paulo apontaram que 70\% dos alunos estão insatisfeitos com o nível de ruídos dentro das salas de aula, sendo que 99,2\% relatam que as maiores fontes de barulho são os próprios colegas. Os estudos ainda constataram que os barulhos em sala de aula podem atingir 80 decibéis (dBs) - o ideal seria no máximo $65 \mathrm{dBs}$-, o que pode ocasionar problemas de audição a longo prazo. (ANUNCIAÇÃO, 2014).

Nossa sala, portanto, era mais uma que sofria com as dificuldades provindas de um ambiente sonoro não saudável. Diante desse quadro, que tanto nos desestabilizava, busquei nos textos de Murray Schafer um caminho a seguir: 
Estou a ponto de sugerir que é chegada a hora, no desenvolvimento da música, de nos ocuparmos tanto com a prevenção dos sons como com sua produção. Observando o sonógrafo do mundo, o novo educador musical incentivará os sons saudáveis à vida humana e se enfurecerá contra aqueles hostis a ela. (SCHAFER, 1991, p.123)

A partir disso, alguns questionamentos vieram à tona. Será que eu estava de fato em um ambiente de muita poluição sonora? Será que nós mesmos (eu e as crianças) éramos os principais causadores desse "barulho" todo? Será que poderíamos transformar aquele ambiente em um ambiente de sons saudáveis? O que é propriamente um som saudável em uma escola infantil? O que exatamente entendemos por som e barulho?

Buscando responder a essas questões, encontrei as seguintes definições:

Som: 1. Fenômeno acústico que consiste na propagação de ondas sonoras produzidas por um corpo que vibra em meio material elástico (especialmente o ar) 2. Sensação auditiva criada por esse fenômeno;

Ruído: 1. Barulho provocado pela queda de um corpo. 3. Rumor contínuo e prolongado, bulício. 9. Fís. Som constituído por grande número de vibrações acústicas com relações de amplitude e fase distribuídas ao acaso.

Barulho: 1. Ruído, rumor. 2. Tumulto, desordem, alvoroço. 3. Motim, revolta. 4. Mistura desordenada de objetos. 5. Alarde, ostentação. (AURÉLIO, 1986)

A primeira impressão ao ler tais verbetes é que as definições de dicionário não conseguem captar a complexidade dessas sensações sonoras. Afinal, elas dependem de uma multiplicidade de interpretações culturais nas quais o próprio conceito do que é música é variável. Segundo o professor e pesquisador José Miguel Wisnik:

A música, em sua história, é uma longa conversa entre o som e o ruído. Som e ruído não se opõem absolutamente na natureza: trata-se de um continuum, uma passagem gradativa que as culturas irão administrar, definindo no interior de cada uma qual a margem de separação entre as duas categorias. (WISNIK, 1989, p.30) 
Apesar do barulho constante da escola e mesmo consciente dessa simbiose inevitável entre som e ruído, eu procurei, a princípio, criar momentos de quietude e atenção com as crianças, para podermos melhor distinguir tais sensações. Com isso, eu buscava, em minhas práticas pedagógicas, um ambiente sonoro saudável, de escuta ativa, onde as crianças pudessem ampliar suas percepções para tudo o que acontecia ao redor. Afinal, como afirma Celso Favaretto:

\footnotetext{
A escuta não pode ser assimilada à audição distraída; ao comportamento generalizado tomado como natural; a escuta exige atenção e concentração, é uma força estranha que através de vibrações audíveis e inaudíveis, de vozes e silêncios, convoca o corpo, conecta o inconsciente. (FAVARETTO, 2012, p. 48)
}

Mas, como encontrar essa escuta coletiva? Ao tentar atrair a atenção de todos, em um dia de roda de conversa, uma das minhas alunas trouxe a solução fácil: "Professora, é só falar pra passar um ziper na boca, assim ob, zip, zip, zap, a boquinha vai fechar." Eu agradeci a sugestão, mas gostaria de algo menos démodé já que eu aprendera o zip zip zap há 30 anos, quando tinha a idade dos meus alunos, e não era por esse caminho que gostaria de seguir trabalhando. Além disso, a quietude pela obrigação, vindo de cima para baixo, poderia contribuir para o enrijecimento dos corpos daquelas crianças. Como eles iriam participar da roda de conversa com as bocas travadas por zíperes?

No início de 2019, a prefeitura lançou o novo Currículo da Cidade para a Educação Infantil. Tal documento foi elaborado por professores da rede municipal de ensino e discutido durante todo o ano de 2018 dentro das escolas. O principal ponto desse texto tem a premissa de que a criança deve ser protagonista de seu saber, valorizando "o papel das(os) educadoras(es) da primeira infância, compreendendo que o protagonismo infantil ocorre simultaneamente ao protagonismo docente, numa relação de interdependência e sem subordinações" (SÃO PAULO, 2019, p. 12). Munida dessa premissa, mantive meu olhar atento às crianças e às relações que elas estabeleciam no dia a dia escolar. O norte, para o caminho que eu deveria seguir, veio com um convite para assistir a uma apresentação do Projeto Guri. O projeto, que tem um polo no CEU onde eu lecionava, atende crianças e adolescentes no contra turno escolar com 
cursos de iniciação musical, luteria, canto coral, tecnologia em música, instrumentos de cordas dedilhadas, cordas friccionadas, sopros, teclados e percussão. Eufóricas com a possibilidade de ir ao teatro, as crianças reagiram com entusiasmo aos diversos instrumentos que estavam a sua frente. Alguns cantarolaram as músicas que conheciam junto ao coral, outros seguiram os músicos ou o maestro com gestos coordenados. Ao final da apresentação, fizemos uma roda de conversa muito rica. As crianças falaram sobre os instrumentos, imitaram os sons e também lembraram do maestro. Um dos alunos explicou aos colegas "Ele desenha a música com o palito". Compreendemos, a partir da roda de conversa, que o maestro ajuda os músicos a saberem quando começar, quando é hora de parar, e qual instrumento deve ser tocado. Mostrei para as crianças como era o gesto para iniciar e o gesto para parar e brincamos um pouco com isso. Ao final da conversa, eu compreendi que deveria iniciar um projeto de música com aquele grupo.

Retomei os textos e autores que estudei nas aulas de Música da Especialização em Arte na Educação: Teoria e Prática, realizada nos anos de 2015 a 2017, na Universidade de São Paulo, para estruturar um projeto e o ramifiquei em momentos de prática da escuta e em momentos de escuta da prática. Assim como Murray Schafer organizou com seus alunos universitários listas para catalogar os sons ouvidos, também separei por temas o foco que iríamos dar para as nossas práticas de ouvir. Como diz o autor: "Os sons ouvidos podiam ser divididos em sons produzidos pela natureza, por seres humanos e por engenhocas elétricas.” (SCHAFER, 1991, p. 125). Iniciamos com os sons produzidos pelos seres humanos. Esperei o momento de maior silêncio dentro da sala, (quando outras turmas estavam na área externa brincando) para perguntar às crianças que sons eram esses. Nossa primeira lista ficou assim:

Coração
Pé batendo no chão
Assobiar
Pum
Gritar
Bater Palmas
Soprar o nariz
A Barriga


A cada som sugerido pelas crianças, o grupo experimentava na prática. Assim sendo, elas exploravam um pouco aquele som, e quando eu fazia o gesto do maestro de parar, elas paravam, dando a oportunidade de outra criança sugerir um novo som. No começo, isso foi acontecendo aos poucos, depois foi cada vez mais fácil para elas entenderem que era hora de parar para ouvir a próxima criança. Nossa primeira lista gerou risos sobre o som do pum; gerou desafios, como quando a única criança que sabia assobiar mostrou sua habilidade e todos ficaram um bom tempo tentando imitar; também gerou curiosidade, como quando as crianças, em duplas, tentaram ouvir outros sons de dentro do corpo, colocando o ouvido no corpo do colega e procurando os sons (foi como encontraram o som da barriga).

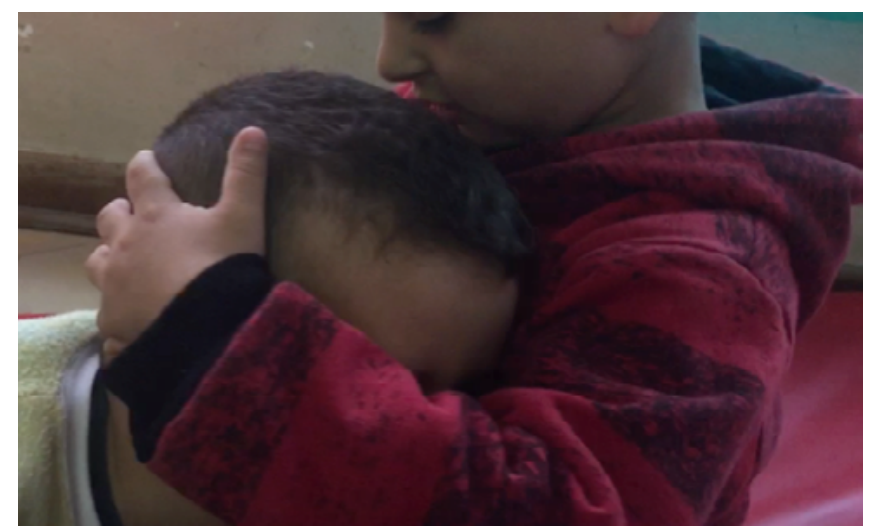

Figura 1 - O som do coração, acervo pessoal, 2018.

Também levei, para a apreciação das crianças, vídeos de alguns grupos musicais que trabalham apenas com os sons corporais e/ou com a voz, como Barbatuques e Grupo Fritos. Os pequenos ficaram muito atentos à TV e imitaram os gestos e os ritmos de maneira livre.

Iniciamos nossa segunda lista ainda na sala de referência. Sem pedir que as crianças fizessem silêncio, sem pedir que se aquietassem, apenas em roda, eu pedi a elas que fechassem os olhos e ouvissem os sons ao redor. Enquanto Murray Schafer (1991), com seus alunos, enfrentava dificuldades em descrever os sons do cotidiano em suas singularidades e minuciosidades, os primeiros relatos dos meus alunos me ajudaram a lembrar que eu estava trabalhando com crianças bem pequenas, e que teria que ter paciência, construindo uma paisagem sonora com tranquilidade, respeitando a criatividade deles. Nossa segunda lista de sons foi: 


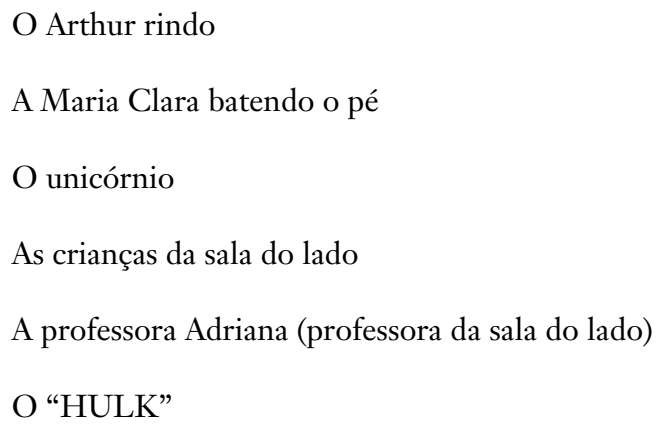

A água do banheiro

Essa lista revelou algo que se repetiu por várias rodas de escuta dos ambientes sonoros. As crianças se propuseram a ouvir, e mesmo sem pedir silêncio, a maioria das crianças tentou ficar quieta, direcionando muitas vezes o corpo todo para os pontos de ruído e som. Entretanto, na hora de descrever o que ouviram, elas não conseguiam relatar sons distantes, como os passarinhos (que sempre era possível ouvir de nossa sala), ou mesmo o som dos carros na rua, mas relatavam sons da imaginação delas, como personagens de desenhos que gostavam de assistir, como o "HULK", os "PJ Masks", "unicórnio" ou de histórias infantis, como a bruxa, a princesa ou o lobo, muitas vezes imitando algum bordão dos personagens.

Realizei essa proposta muitas vezes e, as poucos, fui estimulando que as crianças ampliassem essa escuta, direcionando o que iríamos ouvir daquela vez, mas respeitando sempre os momentos de criatividade, levando em conta que: "O que a criança vê e ouve constitui desse modo os primeiros pontos de apoio para sua criatividade futura. A criança acumula material a partir do qual, posteriormente, irá construir as suas fantasias" (VIGOTSKI, 2014, p.25).

Então, nas aulas, eu sugeria: "Hoje vamos ouvir os sons lá da rua. Hoje vamos ouvir os sons da sala do lado. Hoje vamos ouvir os sons do banheiro". Também fomos explorar os espaços da escola e do CEU. No bosque, tivemos, pela primeira vez na nossa lista, o som do vento, quando pudemos ouvir o vento balançando as folhas das árvores. Os sons do imaginário das crianças não deixaram de aparecer, mas passaram a ser mais relacionados com os lugares onde estávamos. No bosque (que outras professoras chamavam de "bosque do lobo mau") algumas crianças sempre ouviam o uivar do lobo mau. Em um dia de chuva, fizemos a roda de escuta e muitas crianças relataram terem ouvido um trovão, embora não estivesse trovejando naquele dia. 


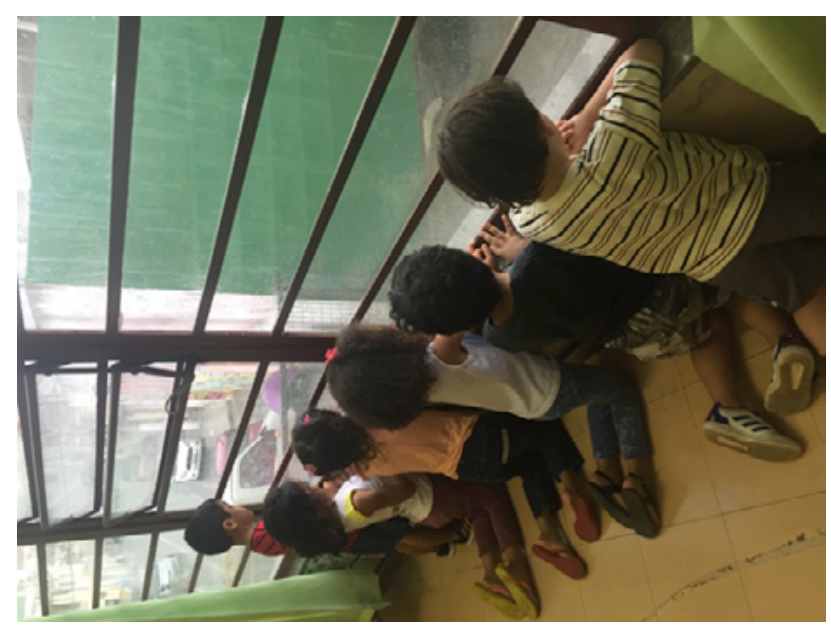

Figura 2 - O som da chuva, acervo pessoal, 2018.

Depois de algumas semanas ouvindo os sons de todos os nossos espaços de convivência, e criando uma grande lista com os sons da natureza, ouvidos, imaginados e lembrados pelos alunos, sugeri uma lista de instrumentos musicais. Primeiro, quis saber quais instrumentos eles conheciam e, a princípio, fizemos uma lista modesta:

\section{Violão \\ Pandeiro \\ Chocalho \\ Tambor \\ Guitarra \\ Flauta \\ Piano}

Ao longo das semanas, levei um a um os instrumentos sugeridos. Todos os instrumentos eram profissionais e estavam em perfeito estado de conservação, alguns emprestados pelo Projeto Guri, outros por mim. Em nenhum momento expliquei como eles deveriam segurar o instrumento ou como ele deveria ser tocado. Também não tinha a intenção de ensinar as crianças as peculiaridades de cada instrumento, apenas de fazer com que elas se familiarizassem com eles. Antes de cada exploração, eu lembrava às crianças que os instrumentos musicais 
eram delicados e que elas deveriam cuidar muito bem deles. Quando observava que alguma ação da criança poderia estragar o instrumento, eu intervinha e, no mais, deixei que os explorassem livremente.

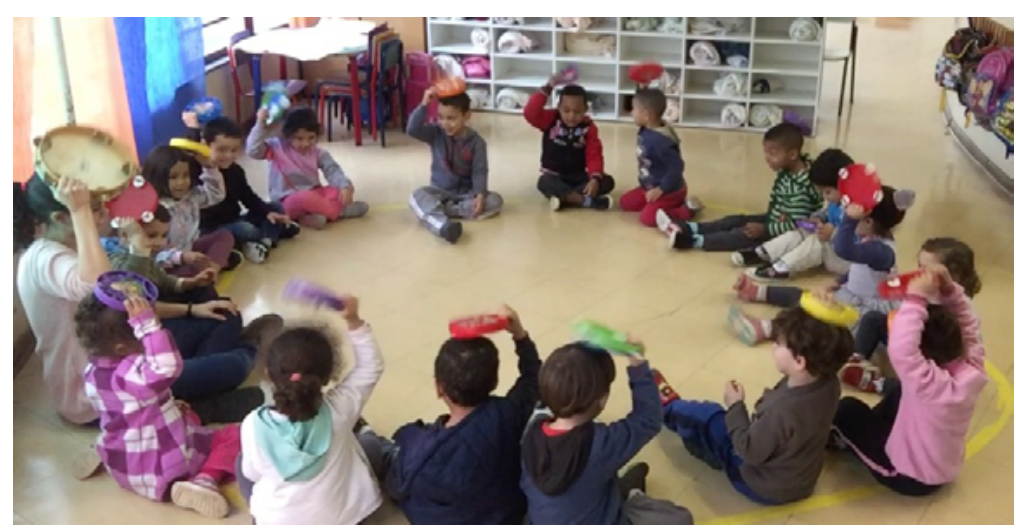

Figura 3 - Jogo de imitação sugerido pelas crianças, acervo pessoal, 2018.

Tais liberdades fizeram com que as crianças não apenas copiassem os padrões dos músicos que elas já haviam visto, como também tentassem novas possibilidades, como tocar o pandeiro com a cabeça, batucar no violão, compreender o som vibrante e abafado do tambor. Também observei que muitas crianças associaram os instrumentos a canções, cantarolando ou tocando no ritmo de alguma música (principalmente as músicas infantis que cantávamos no dia a dia). Notei que cada vez mais as crianças lidavam com a música de maneira "brincante", assim como sugere Teca Alencar de Brito:

A criança é um ser 'brincante' e, brincando, faz música, pois assim se relaciona com o mundo que descobre a cada dia. Fazendo música, ela, metaforicamente, 'transforma-se em sons', num permanente exercício: receptiva e curiosa, a criança pesquisa materiais sonoros, 'descobre instrumentos', inventa e imita motivos melódicos e rítmicos e ouve com prazer a música de todos os povos. (BRITO, 2003, p. 35).

Por fim, quis mostrar para as crianças que era possível fazer música com instrumentos não convencionais. Para isso escolhi vídeos do DVD "Música de Brinquedo”, da Banda Pato Fu e do Grupo TRIII, em que os músicos utilizam diversos instrumentos alternativos em suas 
composições. Os pequenos adoraram os vídeos e as novas músicas, imitaram os músicos com seus instrumentos inusitados e ampliaram seu repertório de canções.

Percebi, ao longo do projeto, que os alunos ficaram cada vez mais atentos, participativos e interessados. As rodas de conversa eram ricas e musicais e as crianças sempre propunham canções relacionadas com as conversas. Meus alunos de três e quatro anos não só estavam cantando juntos, como sugeriam ritmo, batucando com seus corpos e, em algumas ocasiões, também arriscavam alguns improvisos, criando novas canções.

É curioso notar que, a partir do momento em que as crianças conseguiram ouvir os sons da sala, distinguindo cada um e suas características, tais sons passaram a nos incomodar muito menos. No lugar da poluição sonora que nos afligia no começo do ano, demos espaço a um ambiente de criatividade e transformações. Os ruídos puderam ser ressignificados, sendo inseridos nas brincadeiras e se transformaram em música. Organizamos nossos períodos, na sala de referência, de maneira a utilizá-la em horários mais tranquilos, e quando o ambiente estava muito barulhento as próprias crianças sugeriam uma mudança de espaço. Assim, passamos a fazer nossas rodas de conversa e escuta em diversos locais do CEU.

O brincar das crianças também foi permeado por sons e muitos brinquedos, além dos sons externos serem inseridos nas brincadeiras. Tocos de madeira, legos e cordas transformaram-se em baterias, violões ou novos instrumentos, sendo que a música passou a ser um elemento significativo no universo imaginativo dos alunos.

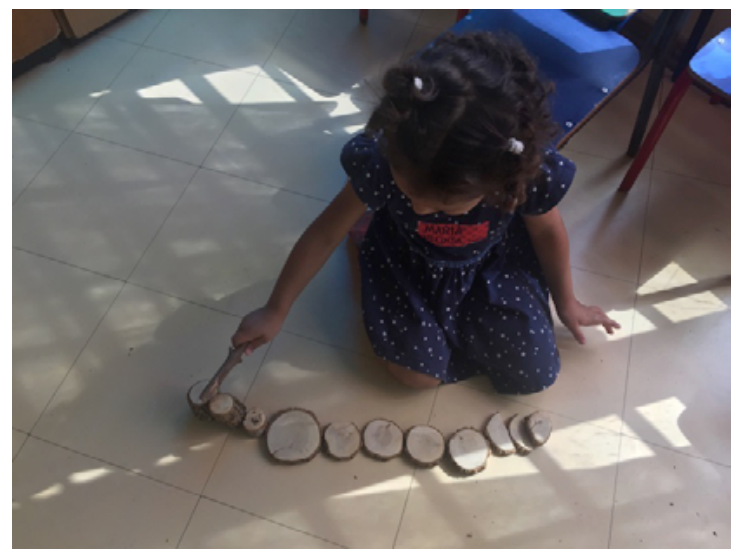

Figura 4 - Transformando brinquedos em instrumento, acervo pessoal, 2018. 
Nossas vivências musicais ressoaram para além dos limites da nossa sala, quando alguns professores da escola se mobilizaram para criar um Parque Sonoro. A iniciativa faz parte de um projeto da Secretaria de Educação da Prefeitura de São Paulo, que visa ampliar as brincadeiras musicais das crianças, criando ambientes repletos de objetos sonoros presentes no dia a dia dos pequenos. Com isso, chaves, panelas, tampas, latas e tocos transformaram-se em mais uma possibilidade de exploração musical para nossos alunos.

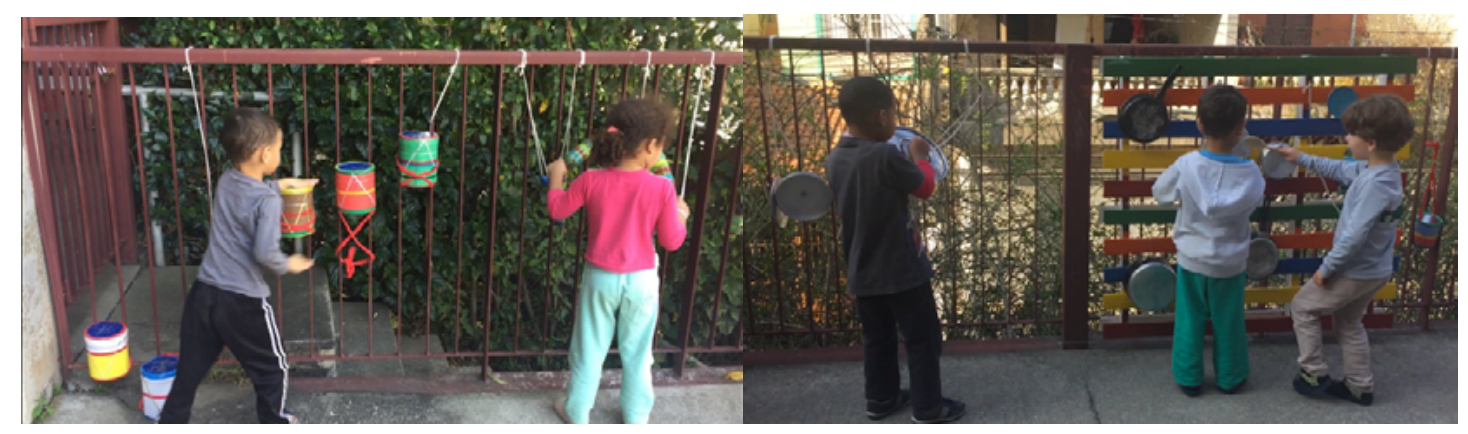

Figura 5 e 6 - Explorando o Parque Sonoro, acervo pessoal, 2018.

Vale ressaltar que o estabelecimento de uma rotina foi essencial para que os pequenos se habituassem às atividades propostas. Como em todos os dias eu os convidava para sentar em roda, cantando uma música, e sugerindo que fechassem os olhos e abrissem as orelhas, isso virou algo que eles já esperavam que iria acontecer, sendo que algumas vezes eles mesmo perguntavam: "Prô, é hora da roda de ouvir?", e chamavam os colegas mais dispersos para participar. As famílias também relataram que as crianças passaram a demonstrar mais interesse por música em geral, brincando com percussão corporal ou dizendo que instrumento estava sendo tocado enquanto ouviam uma canção no rádio ou celular.

Durante os meses que o projeto foi realizado, relacionei as listas a outras atividades artísticas como o desenho, a pintura e a dança, o que gerou mais pontos de convergência dentro do fazer das crianças, possibilitando que ampliássemos nossa escuta para todo o corpo.

Ao final desse período letivo, acredito que tivemos a oportunidade de aprender juntos, professora e alunos, compartilhando paisagens sonoras e transformando ruídos em possibilidades de aprendizado. Não alcançamos um hipotético silêncio, ou uma quietude passiva, 
mas recheamos nosso dia a dia com sons mais saudáveis, de uma forma criativa e prazerosa. O barulho já não nos era tão hostil. Havíamos criado música a partir do barulho. E silêncios a partir da música. 


\section{Referências}

ANUNCIAÇÃO, Silvio. Ruídos em aula afetam e incomodam estudantes. $\mathrm{N}^{\circ}$ 593. Campinas: Jornal da Unicamp, 2014. Disponível em https://www.unicamp.br/unicamp/ju/593/ruidos-em-aula-afetam-e-incomodam-estudantes. Acesso em: 14 agosto. 2018.

AURÉRIO, Buarque de Holanda Ferreira. Novo Dicionário da Lingua Portuguesa. 2. ed. Rio de Janeiro: Nova Fronteira, 1986.

BRITO, Teca Alencar de. Música na educação infantil. São Paulo: Peirópolis, 2003.

FAVARETTO, Celso. Música na escolar: Por que estudar música? In: JORDÃO, Gisele, ALUCCI, Renata R., MOLINA, Sergio, TERAHATA, Adriana Miritello (Coordenadores). A Música na Escola. São Paulo: Allucci \& Associados Comunicações, 2012.

MALAGUZZI, Loris. História, ideias e filosofia básica. In: EDWARDS, Carolyn, GANDINI, Lella, FORMAN, George. As cem linguagens da criança: a abordagem de Reggio Emilia na educação da primeira infância. Porto Alegre: Artes Médicas Sul, 1999. 59-104.

SÃO PAULO (SP). Secretaria Municipal de Educação. Coordenadoria Pedagógica. Currículo da Cidade: Educação Infantil. São Paulo: SME/COPED, 2019.

SCHAFER, R. Murray. O ouvido pensante. São Paulo: Universidade Estadual Paulista, 1991. VIGOTSKI, L. S. Imaginação e criatividade na infância. São Paulo: Martins Fontes, 2014.

WISNIK, J. M. O som e o sentido: uma outra bistória das músicas. 2. ed. São Paulo: Companhia das Letras, 1989. 